\title{
Effects of emergency remote instruction during the COVID-19 pandemic on university physics students in Italy
}

\author{
Irene Marzoliø, ${ }^{1}$ Arturo Colantonio $\odot,{ }^{1,2}$ Claudio Fazio $\odot,{ }^{3}$ Marco Giliberti, ${ }^{4}$ \\ Umberto Scotti di Uccio, ${ }^{5}$ and Italo Testa $\circledast^{2,5, *}$ \\ ${ }^{1}$ School of Science and Technology, Physics Division, University of Camerino, Camerino 62032, Italy \\ ${ }^{2}$ INAF-Astronomical Observatory of Capodimonte, Naples 80131, Italy \\ ${ }^{3}$ Department of Physics and Chemistry E. Segrè, University of Palermo, Palermo 90128, Italy \\ ${ }^{4}$ Department of Physics A. Pontremoli, State University of Milan, Milano 20133, Italy \\ ${ }^{5}$ Department of Physics E. Pancini, University Federico II, Naples 80126, Italy
}

(Received 25 March 2021; accepted 2 September 2021; published 13 October 2021)

\begin{abstract}
We surveyed a convenience sample of 362 Italian university physics students, asking them to retrospectively assess their experience of emergency remote instruction due to the COVID-19 outbreak. We looked at their psychological well being, motivation for physics, academic orientation, attitude towards physics and physicists, and tried to link these factors to their overall perception of the online instruction. Our results show a general appreciation for the organization and effectiveness of online courses. However, online teaching negatively impacted on engagement and interaction between peers and with the instructors. Only $22 \%$ of students in our sample complained of the psychological distress due to remote instruction. Nonetheless, we found a significant decrease in motivational dimensions, such as interest and recognition. Emergency remote instruction also challenged the students' self-regulation, self-efficacy, and engagement. Finally, the uncertainty about the future resulted in a more pessimistic attitude towards physics, academic performance, and job perspectives.
\end{abstract}

DOI: 10.1103/PhysRevPhysEducRes.17.020130

\section{INTRODUCTION}

The COVID-19 pandemic [1-3] compelled many universities worldwide to move from face-to-face to online classes [4-7]. This shift forced university instructors to deliver their courses in a remote modality without a suitable preparation of the didactic materials $[8,9]$. However, the abrupt transition also influenced students' habits, who struggled to deal with and to adjust to online learning $[10,11]$. Many papers in science education described the challenges of this global transition. For instance, in a special issue of the Journal of Chemical Education in early September 2020, an impressive number of papers describe online and blended courses designed to address the emergency situation [12].

In the field of physics education, a few papers report about how in-person laboratory approaches were shifted online $[13,14]$. Far less effort has been devoted to investigating students' perception of remote learning. In a recent study [15] with 578 European physics students, the authors

*italo.testa@unina.it

Published by the American Physical Society under the terms of the Creative Commons Attribution 4.0 International license. Further distribution of this work must maintain attribution to the author(s) and the published article's title, journal citation, and DOI. found that first-year students performance perception was significantly lower than those of older students. Moreover, they also found a positive correlation between the achievement perception and students' metacognitive abilities. Finally, the authors found also a positive correlation between the perceived effectiveness of the online lectures and performance perception. Differently, the study in Ref. [16] investigated the challenges encountered by second-year students enrolled in a chemistry course, as well as their engagement and well-being during the remote learning period. The results show that most students viewed the online experience as unpleasant and as a source of stress that increased their anxiety and lowered their interest and engagement. This result echoes those of recently published studies worldwide [17-25], which show that students' psychological well being was threaten by the COVID-19 disease and related public health interventions (physical distancing, stay-at-home orders, etc.) through diminished concentration, sleep deprivation, decreased interaction, and concerns about academic performance. However, the consequences of the COVID-19 pandemic on students' mental health and psychological well-being over the long run are still uncertain. In Italy, a recent study [26] showed that the effects of lockdown quickly vanished as measures were lifted. In particular, anxiety and obsessive symptoms were not aggravated by lockdown measures. 
Despite the valuable insights that such an increasing body of knowledge provides, several aspects of the emergency remote instruction experience still need to be investigated. First, preliminary studies (e.g., [27,28]) only hint at some factors but do not provide a clear picture of the main dimensions of the students' perception of the emergency remote instruction experience. Second, prior studies have not addressed how such perceptions are related to changes in psychological well being due to the COVID-19 pandemic and government measures. Third, whether the emergency remote instruction experience impacted on students' motivation, orientation, and attitudes received scant attention [28]. Finally, it is not clear the extent to which such changes affected the perception of the emergency remote instruction experience as a whole.

This paper aims to address these issues focusing on university physics students ex-post assessment of the emergency remote instruction. The reason is that the university physics community in Italy is generally characterized by a tight relationship between classmates and between students and instructors, with laboratory practice as a strengthening factor. The forced closure of university departments and consequent social distancing due to lockdown measures could have had a deeper impact on the physics community. To this end, we adopted a retrospective pretest-post-test design [29] to compare students' perceptions about their well being, motivation, academic orientation, and attitude towards physics before and after the online experience.

The teaching period taken into consideration is the second semester of the academic year 2019-2020, from March to June 2020. In Italy, the nationwide lockdown began on March 9th, so, in most universities, second semester courses started directly in the online modality. Despite that most stringent restrictions were gradually released from May 2020, university courses were concluded in the online modality, with very few exceptions limited to laboratory activity.

The following research questions (RQ) guided the study:

- RQ1: What is the university students' perception of the emergency remote instruction?

- RQ2: How are the changes-if any-in students' subjective well being related to their perception of the emergency remote instruction?

- RQ3: How did the emergency remote instruction experience impact on students' motivation in learning physics?

- RQ4: How did the emergency remote instruction experience impact on students' academic orientation towards physics?

- RQ5: How did the emergency remote instruction experience impact on students' general attitude toward physics and physicists?

- RQ6: How are the changes in the general attitude toward physics, if any, related to students' perception of the emergency remote instruction, and to changes in (a) subjective well being, (b) motivation to learn physics, (c) academic orientation towards physics?

\section{METHODS}

\section{A. Variables definition and instrumentation}

In the following, we describe how the constructs relevant to the present study were conceptualized and measured, and present the used instrument (see Supplemental Material for more details [30]). At the end of the survey, before asking for socio-demographic information, participants were given the opportunity to offer their suggestions for improving remote instruction through an optional open-ended prompt. It is beyond the scope of this paper to analyze these responses. However, we will report a few relevant responses to support our discussion.

\section{Evaluation of the emergency remote instruction experience}

The perception of the whole distance learning experience during the second semester of the 2019-2020 academic year was measured through a 12 -item scale adapted from previous surveys [16,31]. Starting from the results of these prior works, we hypothesized that the items could be grouped in a three-factor structure: (i) effectiveness and organization of the courses; (ii) relationship with the instructors; (iii) perceived difficulties due to remote instruction modality. Respondents were asked to compare each aspect, targeted by the 12 items, before and after the remote teaching experience on a 5-point Likert scale (see Supplemental Material [30]).

\section{Subjective well being (SWB)}

In psychology research, SWB is conceptualized as a twodimensional construct [32], which includes positive and negative affects. Positive affect measures the extent to which a person feels enthusiastic, engaged, or active in a given situation. Negative affect refers to subjective anguish, anger, and anxiety felt in a given situation. SWB is usually measured through positive and negative affect schedule (PANAS) self-reported scales. PANAS scales are constituted by adjectives that describe a positive or negative affect. For the present study, we used an extended version of the PANAS scale described in Ref. [33] including 30 descriptors. Subjects in our study were asked to rate on a 1 (definitely less) to 5 (definitely more) Likert scale the extent to which each item described their feelings or mood, when they were involved in distance learning activities compared to in-person activities. Examples of adopted descriptors are distressed, excited, stimulated, accepted, valued, respected, guilty, and upset. 


\section{Motivation to learn physics}

In this study, we conceptualized motivation to learn physics as the tendency of students to consider academic activities relevant and valuable and to look for benefits from them [34]. Following prior work done in Italian context [35], we developed a scale inspired to the work by Glynn and colleagues [36,37], adapting in particular the items of the intrinsic motivation and personal relevance subscale. We divided the adapted items into two subscales: (a) interest and (b) utility value. The main reason was to obtain a more refined description of the students' perception of their own motivation to learn physics. A further reason was that these constructs have been studied separately in previous works $[38,39]$. During the item development process, we included also a third dimensionrecognition-since this factor is increasingly attracting attention of researchers as an important predictor of career choice [40-42] and of whether students view themselves as a physicist $[43,44]$, which in turn is affected by interest. In the following, we describe the three constructs that constitute the proposed scale.

Interest.--Interest is generally defined as the "preference to engage in some types of activities rather than others" Gardner and Tamir [45] (p. 410). Other researchers conceptualized interest as a psychological state and the tendency to engage in a given situation or content over time [46]. As such, interest can be categorized into situational or individual interest [47]. Situational interest is related to a specific situation that stimulates short-term attention. Instead, individual interest involves a long-term engagement. For this study, we limited our attention to individual interest. We used three items in which we asked respondents to gauge, on a 5-point Likert scale ( $1=$ not at all; $5=$ very much), their interest for physics topics, physics research studies, and physics-related hobbies, before and after the remote teaching learning experience.

Utility value.-Utility value can be conceptualized as a form of identified regulation; namely, an autonomous form of motivation that consists in attributing personal relevance to the enacted behavior [48]. Similarly, in the expectancy-value model [49-51] utility value refers to how helpful a certain content or activity is to the aim of reaching an external goal. In our study, we focused on a future career as a physicist [52]. We measured utility value by means of two items asking students to rate on a 5-point Likert scale $(1=$ not at all; $5=$ very much) how learning physics is useful for their future career before and after remote instruction.

Recognition.-Finally, prior work in social psychology conceptualizes recognition as one's own perception of how others (for instance, peers, teachers, parents, experts) view them in relation to the discipline, in our case physics. In this study, we measured recognition using two items, in which we asked respondents to rate on a 5-point Likert scale $(1=$ notat all; $5=$ very much $)$ their perception of classmates and university teachers opinion on their ability as physics students, before and after remote instruction.

\section{Academic orientation towards physics}

For this study, we developed a multiscale instrument designed to investigate how various aspects of students' academic learning experience changed in a remote teaching situation. We termed this instrument the physics academic orientation inventory (PAOI). From the theoretical viewpoint, the PAOI builds on the literature on metacognition [53], self-efficacy in monitoring self-regulated learning process [54], and engagement in learning [55]. In terms of scales and structure, the PAOI builds on prior questionnaires developed in the Italian context [56,57] and on physics-related multiscale instruments, such as the SEMLI-S, PMI, and PACS [58-60]. Specifically, the items were adapted or newly developed (see below) to measure five dimensions that define, in a broader way, how students manage their own learning while attending university courses: namely, (a) self-regulated learning, (b) metacognition, (c) self-efficacy, (d) engagement, and (e) anxiety. As also briefly recalled in the introduction, the main reason for including the first three dimensions is that remote instruction can affect students' capability to monitoring, evaluating, and planning their own learning $[61,62]$, as well as the perception of their capability of performing a task [28]. A second reason is that these three constructs are highly correlated and may significantly impact on academic achievement $[36,63,64]$. The reason for including the engagement dimension is that it may be affected by the perceived social support, the quality of the online instruction and self-efficacy [65]. Finally, the reason for including the anxiety dimension is that prior work has shown that remote distance learning lead college students to experience increased anxiety, fear, and worry [20,66-68]. In our survey, we asked the students to report their perceptions in all the chosen dimensions during face-to-face and remote learning activities.

Self-regulated learning.- It can be defined as the set of strategies carried out by an individual to acquire an academic competence or goal (such as passing an exam). In other words, the process of self-regulation is a continuous monitoring of one's own effectiveness [69]. We measured self-regulated learning by means of a 6-item subscale adapted from the self-efficacy and metacognition learning inventory-Science (SEMLI-S) developed by Ref. [58] (see Supplemental Material [30]).

Metacognition.- - It can be defined as the capability to control the personal cognitive processes in a given task [70]. In our study we were interested, in particular, in the regulation of cognition; namely, the actions a student takes to control learning or problem-solving activities [71]. We measured metacognition using a 10-item subscale adapted from Ref. [59] (see Supplemental Material [30]). 
Self-efficacy.-It is defined as the belief in one's own capability to perform a given task [72-74]. As a measure of competence belief, self-efficacy is content and context specific. To measure it, we used a 4-item subscale adapted from Ref. [37] (see Supplemental Material [30]).

Engagement.-Generally, it refers to the extent to which a student participates in academic activities [75]. Given the aims of the study, we focused on students' behavioral engagement: in particular, the active participation during classes. To this end we adapted to the physics context three items of the university student engagement inventory (USEI) [75] (see Supplemental Material [30]).

Anxiety.-Finally, anxiety is an emotional and physiological state that includes feelings of worry, concern, and a general negative affect that occurs when the student engages in a specific activity (for instance, taking a test or, as in our case, the emergency remote teaching classes) [76]. For this study, we adapted two items from the science motivation questionnaire by Glynn and Koballa [37] (see Supplemental Material [30]).

\section{Attitude toward physics}

The attitude toward physics is defined as the set of evaluative judgments, formed by someone about physics [77]. For the present study, we conceptualized the attitude towards physics as a sense making process that shapes experience $[78,79]$. A sense making process is an interpretation process that links the emotional level of experience with the formal level of cognition [80]. We measured the attitude towards physics using a survey instrument, recently validated by our group [81] whose 36 items measured the respondents' perception of the role of physics and physicists in the society before and after the remote learning experience. We included in the survey seven dimensions [82,83]: (a) the perceived value of physics in today's society; (b) the perceived difficulty of physics as a discipline; (c) the intrinsic interest in physics; (d) the personal relevance of working in a physics-related field; (e) the relevance of learning physics at university; (f) the recognition of the physicists' role in the society; (g) the value of physicists' careers.

\section{B. Sample and procedure}

The study involved a convenience sample of 362 Italian university physics students (mean age was $21.9 \pm 2.1 \mathrm{yr}$ ) from twenty Italian universities (central-northern 69.6\% and central-southern 30.4\%). All together, in Italy during the academic year 2019-2020, there were more than 17000 students enrolled in either a bachelor's or a master's degree in physics [84]. The survey, in Italian, was administered online from October through December 2020, while university courses were held in a mixed in-presence and remote teaching modality. In Italy, remote emergency teaching in the universities was carried out mostly by means of commercial online management systems.
Instructors delivered lectures using slides or a drawing tablet. Written exams were carried out with the help of specific testing software, while, for oral exams, the students could use their own electronic or physical board. We stress that in the Italian university system, oral exams are a major component of students' assessment for most of the courses. Surveillance during the written and oral exams was enacted by using two cameras (e.g., smartphone and laptop). We note, however, that the above settings could vary to a large extent within the same university, so we cannot establish a common trend across the country. Respondents participated in the study on a voluntary basis. The survey was approved by the physics course coordinators of each university, shared with instructors who were teaching courses in the semester and delivered during their classes after a brief introduction. Also instructors agreed to participate on a voluntary basis. When possible, the link to the survey was placed in the online course work space and students were reminded to participate to the survey through periodic emails. The time required to complete the survey was about 20-30 min. This commitment was not rewarded with extra grades or credits.

In Table I we report the sample distribution across university levels at the time of the emergency remote instruction (March-June 2020). We remind that, in Italy, physics students first obtain a bachelor's degree (180 European Credit Transfer System, ECTS. One ECTS roughly corresponds to $8 \mathrm{~h}$ of frontal lessons), which requires three years of full-time studying. After this firstlevel degree, they may continue their studies to obtain a master's degree (120 ECTS), which consists of a further two years. Overall, each year, about 2000 students get their bachelor's degree in physics and, according to official statistics $[84,85]$, about $80 \%$ of physics graduates continue their studies to obtain a master's degree. Students, enrolled in the bachelor's degree of physics, attend mostly physics courses (about 135 ECTS) but also advanced mathematics and calculus courses (about 39 ECTS) and one chemistry course (6 ECTS). In the master's degree, almost all the courses are in the physics area. During the emergency remote teaching, the number of hours per ECTS did not change. About $40.6 \%$ of the surveyed students had already

TABLE I. Students' distribution across university levels. We note that the female students' percentage of respondents $(36.2 \%)$ in our study is slightly larger than the national percentage of female students enrolled in a physics course (31.3\%) [84].

\begin{tabular}{lccr}
\hline \hline Level & Students & Females & Males \\
\hline Overall & 362 & 131 & 231 \\
1st & 48 & 16 & 31 \\
2nd & 50 & 21 & 29 \\
3rd & 118 & 43 & 75 \\
4th & 72 & 25 & 46 \\
5th & 76 & 26 & 50 \\
\hline \hline
\end{tabular}


TABLE II. Students' preference about attending courses and taking exams online or in person.

\begin{tabular}{lccc}
\hline \hline & \multicolumn{3}{c}{ Preference } \\
\cline { 2 - 4 } Activity & Online & In-person & No difference \\
\hline Courses & $27.6 \%$ & $67.7 \%$ & $4.7 \%$ \\
Exams & $15.5 \%$ & $65.7 \%$ & $18.8 \%$ \\
\hline \hline
\end{tabular}

obtained their bachelor's degree, whereas about 13.0\% were freshmen. Respondents were asked about their gender at the end of the survey.

In Table II we show the students' preferences about attending courses and taking exams online or in person.

About $45 \%$ of the respondents used only a laptop, whereas a further $46 \%$ used a laptop in combination with a desktop PC, a smartphone, or a tablet to attend online courses or exams.

Finally, more than half of the respondents (55.5\%) attended the remote sessions while there were three or more persons in the same household.

\section{Data analysis}

First, we computed the descriptive statistics of all measured variables to establish whether they were suitable for further statistical analysis. In particular, for variables to be analyzed through a confirmatory factor analysis (CFA), we inspected deviation from the expected normal behavior by looking at the asymmetry and kurtosis. As reported in the Supplemental Material (Tables S1, S3, and S4 [30]) all variables met this requirement. Differently, for variables to be analyzed with the multiple correspondence analysis (MCA), no assumptions were made on measured variables (see below for more details on the performed analyses).

To answer RQ1 we first carried out a confirmatory factor analysis (CFA) to test the three-factor structure of the evaluation of the online learning experience. Several indices were used to assess the quality of the CFA model fit: chi-square to degrees-of-freedom ratio $\left(\chi^{2} /\right.$ d.o.f. $)$, normed fit index (NFI), incremental fit index (IFI), comparative fit index (CFI), Tucker-Lewis index (TLI), and root-mean-square error of approximation (RMSEA). Values of $\chi^{2} /$ d.o.f. less than 3, CFI, IFI, CFI, and TLI above 0.90 , and RMSEA less than 0.08 are indicative of good model fit $[86,87])$. Then, we performed a Rasch analysis [88] to investigate which items were easier to agree or disagree upon for the students in our sample. The reason for using Rasch analysis instead of the comparison with a benchmark value, such as 3 (i.e., neutral opinion, as done, for instance, in Ref. [28]) is that we cannot assume linearity in the rating scale and, hence, we cannot infer whether 3 is actually representing a neutral position. Goodness of fit was investigated through infit and outfit mean square (MNSQ) statistics, while validity and reliability were assessed through the following indices: person reliability (values greater than 0.5 are recommended), item separation reliability (values should be greater than 3), and person separation (values should be greater than 2). Point-measure (PTMEA) correlation for each item was also calculated to indicate the extent to which the item correlated with the measured construct. Note that the assumption of unidimensionality does hold true in our case, since the items were all intended to measure the evaluation of the online learning experience. All Rasch calculations were carried out using WINSTEPS software [89].

To answer RQ2, we segmented the sample according to their responses to their perceived SWB during the online learning experience survey. Segmentation was carried out through a multiple correspondence analysis (MCA) of the sample responses [90-93] and a hierarchical cluster analysis (CA) [94-97]. Multiple correspondence analysis is an extension of principal component analysis to categorical variables. We used this type of analysis since the items were expressed by categorical response scales; hence, not only the distance between these response scales is not linear, but also a comparison between average scores in the items is inappropriate. In this analysis, no assumptions on the variables are made, since the focus is on the modalities of the variables. As such, variables with a non-normal behavior are included in the analysis, whereas modalities with very low frequencies (typically $\leq 2 \%$ ) are discarded from the analysis to extract the factors. The factorial scores obtained from the MCA were used to perform a hierarchical cluster analysis, aimed at identifying emerging response profiles associated with different groups of individuals. The clustering procedure had the following characteristics: (i) hierarchical divisive, which starts from a subdivision of the sample into two main groups and then proceeds in successive steps; (ii) exclusive, i.e., an individual belongs only to a single cluster; (iii) all individuals belong to at least one cluster; (iv) heterogeneous, i.e., clusters can have different size, shape, and density. Two criteria were used for choosing the final number of clusters: (i) the best partition is the one for which the subsequent subdivision produces a limited increase of the explained variance (here called inertia); (ii) the best partition is the one for which the subsequent subdivision produces at least one cluster with less than $5 \%$ of cases of the sample.

To look for possible correlations between the subjective well being and the perception of the remote instruction experience we carried out a one-way analysis of variance (ANOVA), by comparing the raw scores in the three dimensions of the perception of emergency remote instruction across the psychological wellness profiles. We used the raw scores since we were interested only in differences between the groups. Normality assumption was checked through inspection of descriptive statistics (see Supplemental Material [30]), while assumption of homogeneity of variance was inspected through Levene's test. When the latter 
assumption was not met, we used Welch's $F$ robust test of equality of means.

To answer RQ3, we first tested how well the survey items measured the interest, career in physics utility value, and recognition constructs through a CFA. Then, we compared the students' raw scores before and after the emergency remote instruction using a series of two-tailed paired $t$ tests.

To answer RQ4, we first validated the PAOI factor structure through CFA and compared the raw scores before and after the emergency remote instruction using a series of two-tailed paired $t$ tests.

To answer RQ5 we first segmented the sample according to their responses to the attitude towards physics and physicists survey. To this end, we used MCA and CA, in a similar way to what we did to answer RQ2. Then, we compared the distribution of attitudes' profiles before and after the emergency remote instruction using a McNemarBowker test.

To answer RQ6, we first categorized students according to the change in their attitude toward physics profiles with dummy variables. Then, we inspected the effect of profile changes on each of the three dimensions of the perception of the emergency remote instruction using a regression analysis. Finally, we looked for possible associations between the profile change and SWB categories using a chi-square analysis and inspected the differences in the motivation and academic orientation scores after the emergency remote instruction experience through a one-way ANOVA. Assumptions were checked as described above. The effect size (ES) for the $t$ tests was calculated according to Cohen's $d$ formula [98]

$$
d=\frac{x_{1}-x_{2}}{s},
$$

where $x_{1}$ and $x_{2}$ are the two compared mean values and $s$ is the pooled standard deviation, namely, the weighted average of the standard deviations of the two samples, using the size of the samples as weight. The effect size for the one-way ANOVA was calculated using the $\eta^{2}$ coefficient, namely, the ratio between the variance associated with an effect and the total variance. (Spero di aver capito bene la definizione di effect size per l'ANOVA, come rapporto tra la varianza di un effetto e la varianza totale) All the statistical analyses were carried out through the software SPSS v. 26. Multiple correspondence analysis and cluster analysis were carried out through the SPAD software v. 5.6.

\section{RESULTS}

The descriptive statistics for all the measured variables are reported in the Supplemental Material [30]. Reported uncertainties for the items of the survey are standard deviations. In the following, we report the results according to our research questions.

\section{A. What is the university students' perception of the emergency remote instruction?}

We report in Fig. 1 the factor structure of the perception of emergency remote instruction construct. The CFA confirmed that the three-factor structure fitted well our data $\quad\left(\chi^{2} /\right.$ d.o.f $=2.212 ; \quad \mathrm{NFI}=0.945 ; \quad \mathrm{IFI}=0.969 ;$ $\mathrm{CFI}=0.969 ; \quad \mathrm{TLI}=0.958 ; \quad \mathrm{RMSEA}=0.058) . \quad$ Rasch analysis of the items shows that the data fitted well the model, since no misfitting items were found (see Supplemental Material [30]). The person reliability is 0.88 , the person separation is 2.67 , while item separation is 7.10. All indices are hence excellent. Average item pointmeasure correlation is $0.68(\min =0.60 ; \max =0.76)$, which is an acceptable value. The mean value of the Rasch measure for the effectiveness and organization of the course factor is $-1.01 \pm 0.12$ (st. err.) logit. We note that a negative value on the logit scale means that, overall, students had more than $50 \%$ probability to agree with the items. Hence, we can infer a positive judgment of the emergency remote instruction. Contrarily, the mean value of the Rasch measure for the factor perceived difficulties is $+0.25 \pm 0.16$ (st. err.) logit. A positive value means that, overall, students have less than $50 \%$ probability to agree with the item. Hence, we can infer that students seem to have encountered significant difficulties during the emergency remote instruction experience. Such difficulties seem to be mainly due to a negative perception of their degree program and of their chances of attaining the degree after the COVID-19 pandemic (Rasch measure of the two items: +0.62 and +0.59 logit, respectively). Students have also a less positive perception of their relationship with the instructors during the emergency remote instruction [mean Rasch measure: $+0.14 \pm 0.20$ (st. err.) logit]. In particular, students complained about the instructors' capability to raise interest and interact with them (Rasch measure of the items: +0.42 and +0.79 logit, respectively). Finally, the differences between the average Rasch measure of the three factors are statistically significant $(F=8.063$, d.o.f.: 2 , $9 ; p=0.01)$.

\section{B. How are the changes in students' subjective well being related to their perception of the emergency remote instruction?}

The MCA and CA lead to three SWB profiles:

1. Students who felt negatively affected by the remote instruction experience (22.4\%). This profile is characterized by students who felt extremely less satisfied, enthusiastic, stimulated and extremely more stressed, sad, angry, and frustrated when comparing online and in-person experiences.

2. Students who felt significantly supported when comparing online and in-person experiences $(9.4 \%)$. This profile is characterized by students who felt extremely more proud, effective, satisfied and extremely less secluded, guilty, and frustrated 


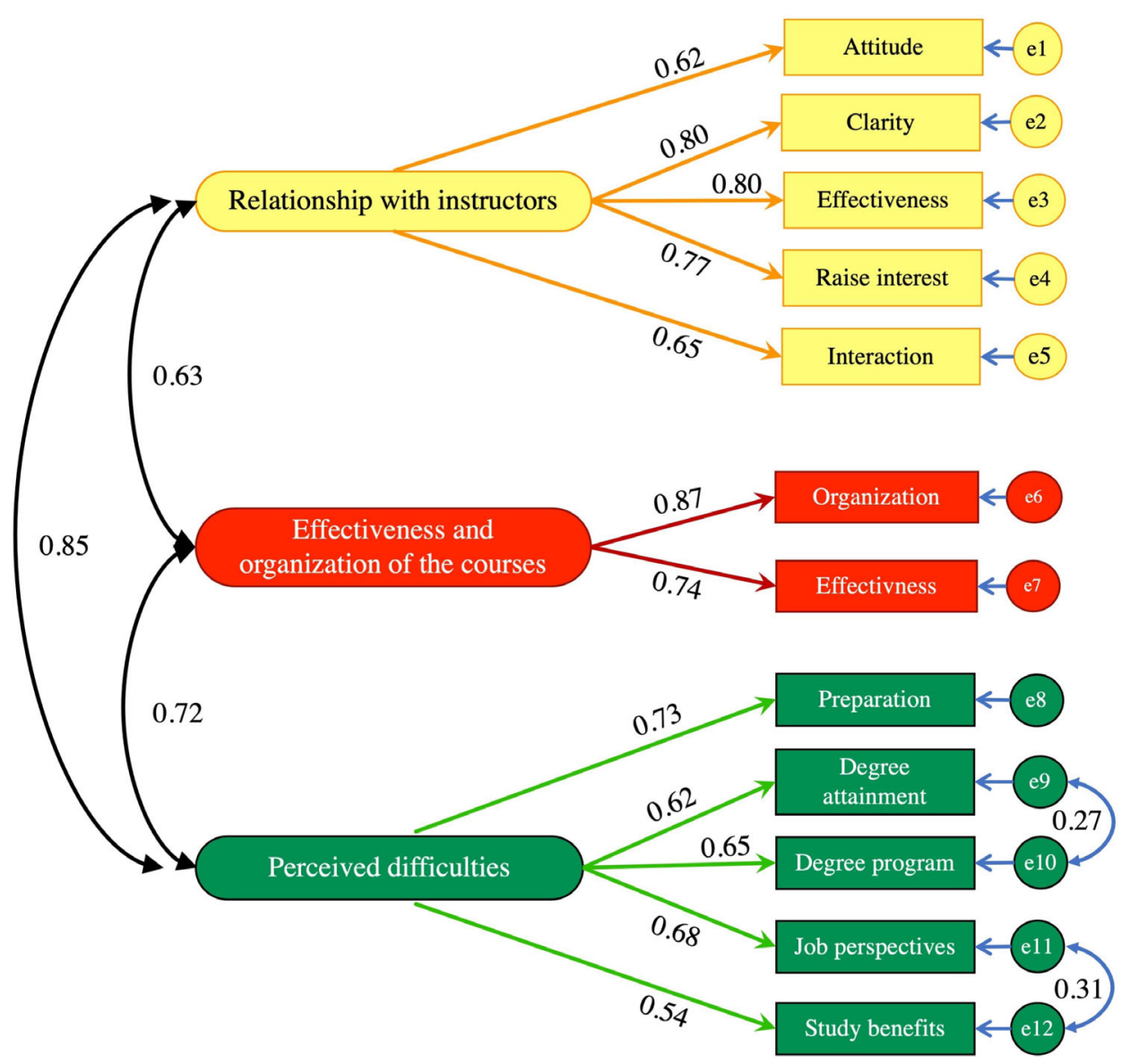

FIG. 1. Factor structure of the perception of emergency remote instruction. The unobserved constructs (factors) are represented by rounded rectangles. The observed variables (i.e., the questionnaire items) are represented by rectangles. The single-headed arrows represent structural regression coefficients, namely, the factorial loads of an observed variable onto the factor. The measurement errors associated to observed variables are represented by a circle and a small single-headed arrow near the corresponding variable. Twoheaded black arrows represent the covariances of the constructs, while two-headed blue arrows represent the error covariances of the items (modification indices).

during the online experience in comparison with inperson courses.

3. Students who were not significantly affected by the emergency remote instruction experience (68.2\%). This profile is characterized by neutral responses to all descriptors of the psychological well-being survey.

Figure 2 reports the average raw scores of the three SWB profiles for the three latent dimensions of the emergency remote instruction perception.

The one-way ANOVA shows that differences across the three SWB groups were significant for all the three latent dimensions, namely, effectiveness and organization of the courses $(F=34.639$, d.o.f. $=2 ; 359, p<0.001)$, perceived difficulties (Welch's $F=71.930$, d.o.f. $=2$; $74.880, p<0.001)$, relationships with the instructors $(F=82.340$, d.o.f. $=2 ; 359, p<0.001)$, with large effect sizes $\left(0.16<\eta^{2}<0.36\right)$. Moreover, for each dimension of the perception of emergency remote instruction construct, the mean values of the SWB profiles are significantly

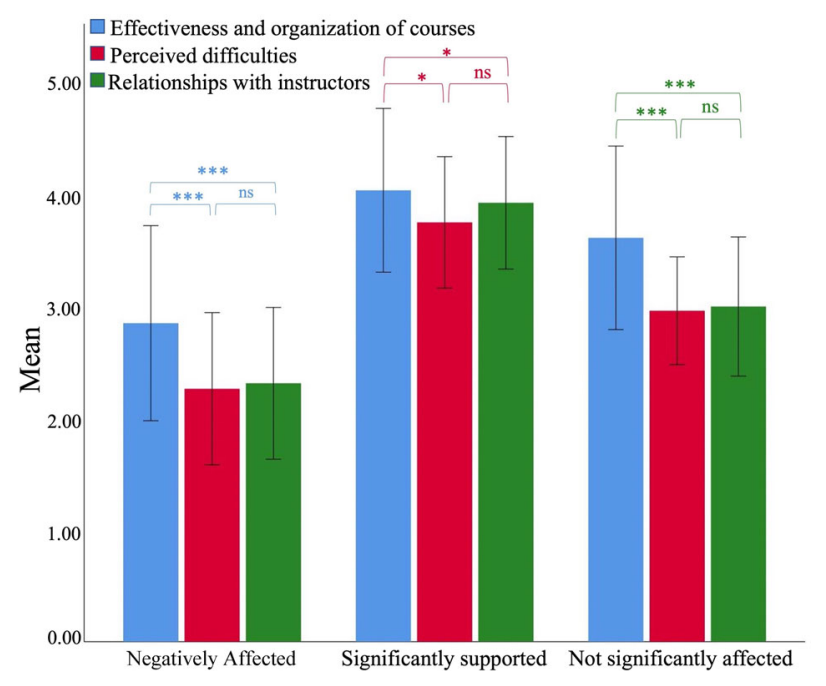

FIG. 2. Mean values of the raw scores of the three SWB profiles for the three latent dimensions of the emergency remote instruction perception. Whiskers are standard deviations. $* p<0.05 ; * * * p<0.001 ; \mathrm{ns}=$ nonsignificant. 


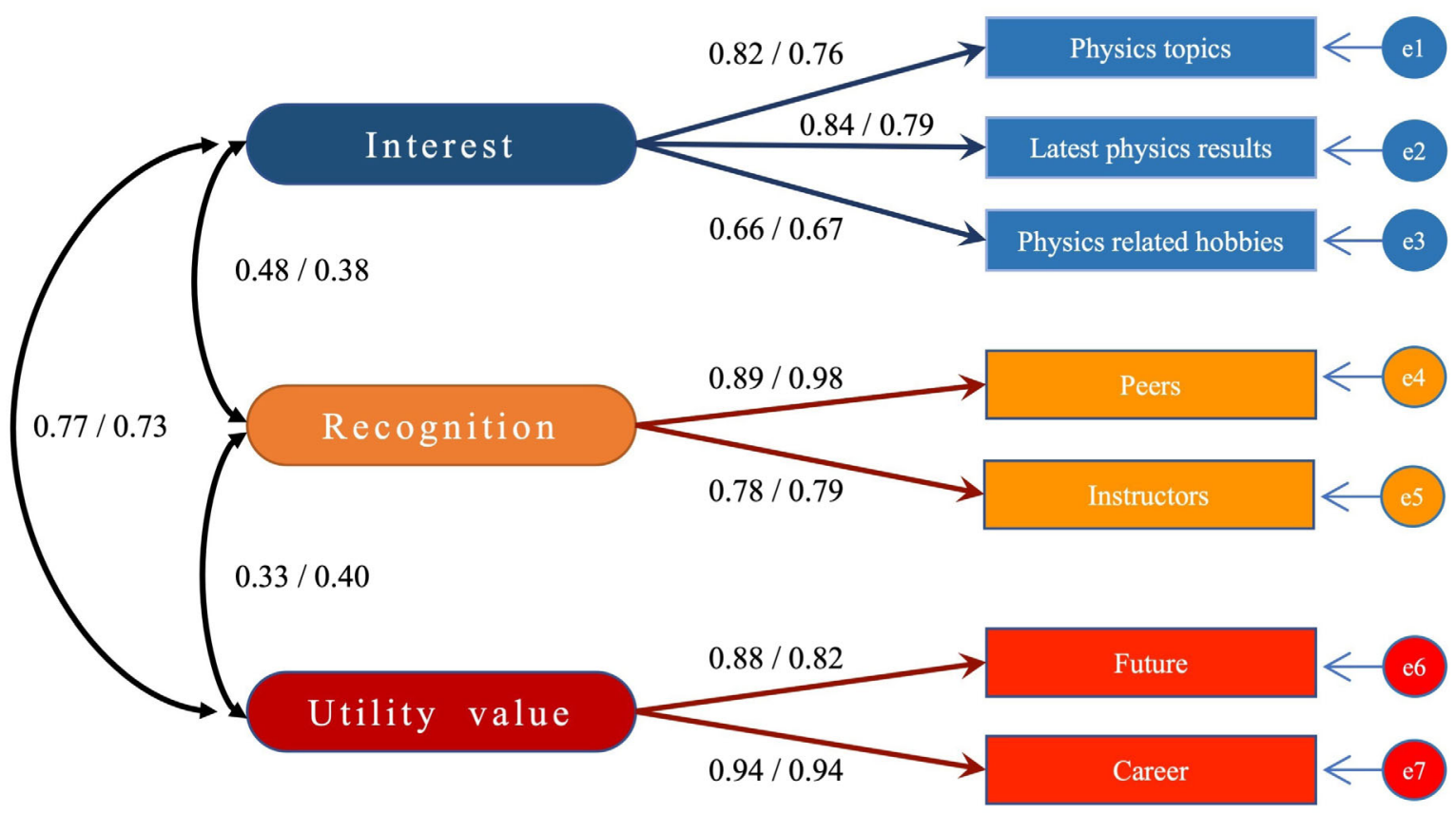

FIG. 3. Factor structure of the motivation to learn physics scale. The unobserved constructs (factors) are represented by rounded rectangles. The observed variables (i.e., the questionnaire items) are represented by rectangles. The single-headed arrows represent structural regression coefficients, namely the factorial loads of an observed variable onto the factor. Factor loadings tell how much the item is related to the factor and should not be confused with item mean values (see Fig. 4). The measurement errors associated to observed variables are represented by a circle and a small single-headed arrow near the corresponding variable. Two-headed black arrows represent the covariances of the constructs. For each factorial load and covariance we reported the value before and during remote instruction.

different. In particular, we consistently found that the average score of the students who felt supported is statistically higher than those of the two other groups of students for all dimensions of the emergency remote instruction perception $(t>2.817$; d.o.f. $=359 ; p<0.005, \mathrm{ES}>0.53)$.

Finally, from Fig. 2, we note that for students in the negatively affected cluster, the score in the perception of

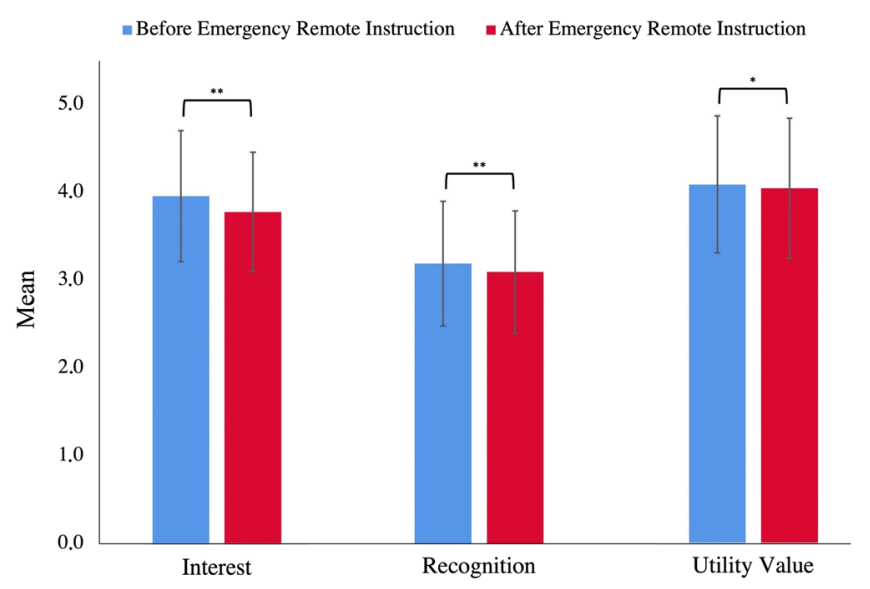

FIG. 4. Mean values of the raw scores of the three latent factors of the motivational construct before and after emergency remote instruction. Whiskers indicate standard deviation. $* p<0.05$; $* * p<0.01$. organizational effectiveness factor is significantly higher than the score in the perceived difficulty and in the relationships with the instructors factors $(t>5.530$; d.o.f. $=80 ; \quad p<0.001,0.69<\mathrm{ES}<0.75$ ), while the difference between the latter dimensions is not statistically significant $(t=-0.661$; d.o.f. $=80 ; p=0.511)$. We found a similar trend for students in the not significantly affected cluster: namely, the score in the perceived effectiveness of course organization is significantly higher than the scores in the perceived difficulty and relationships with the instructors dimensions with larger effect sizes $(t>11.903$; d.o.f. $=246 ; p<0.001 ; 0.85<\mathrm{ES}<0.97)$. For students in the supported cluster, as expected, the average score in the perceived difficulty dimension is significantly lower than the score in the perception of organizational effectiveness and in the relationships with the instructors dimensions $(t>2.125$; d.o.f. $=33 ; p<0.041 ; 0.30<\mathrm{ES}<0.44$ ).

\section{How did the emergency remote instruction experience impact on students' motivation to learn physics?}

We report in Fig. 3 the general factor structure of the motivational construct. The CFA confirmed that the threefactor structure of the motivational construct fit well our data (before remote instruction: $\chi^{2} /$ d.o.f. $=1.769$; $\mathrm{NFI}=0.984 ; \quad \mathrm{IFI}=0.993 ; \quad \mathrm{CFI}=0.993 ; \quad \mathrm{TLI}=0.986$; 


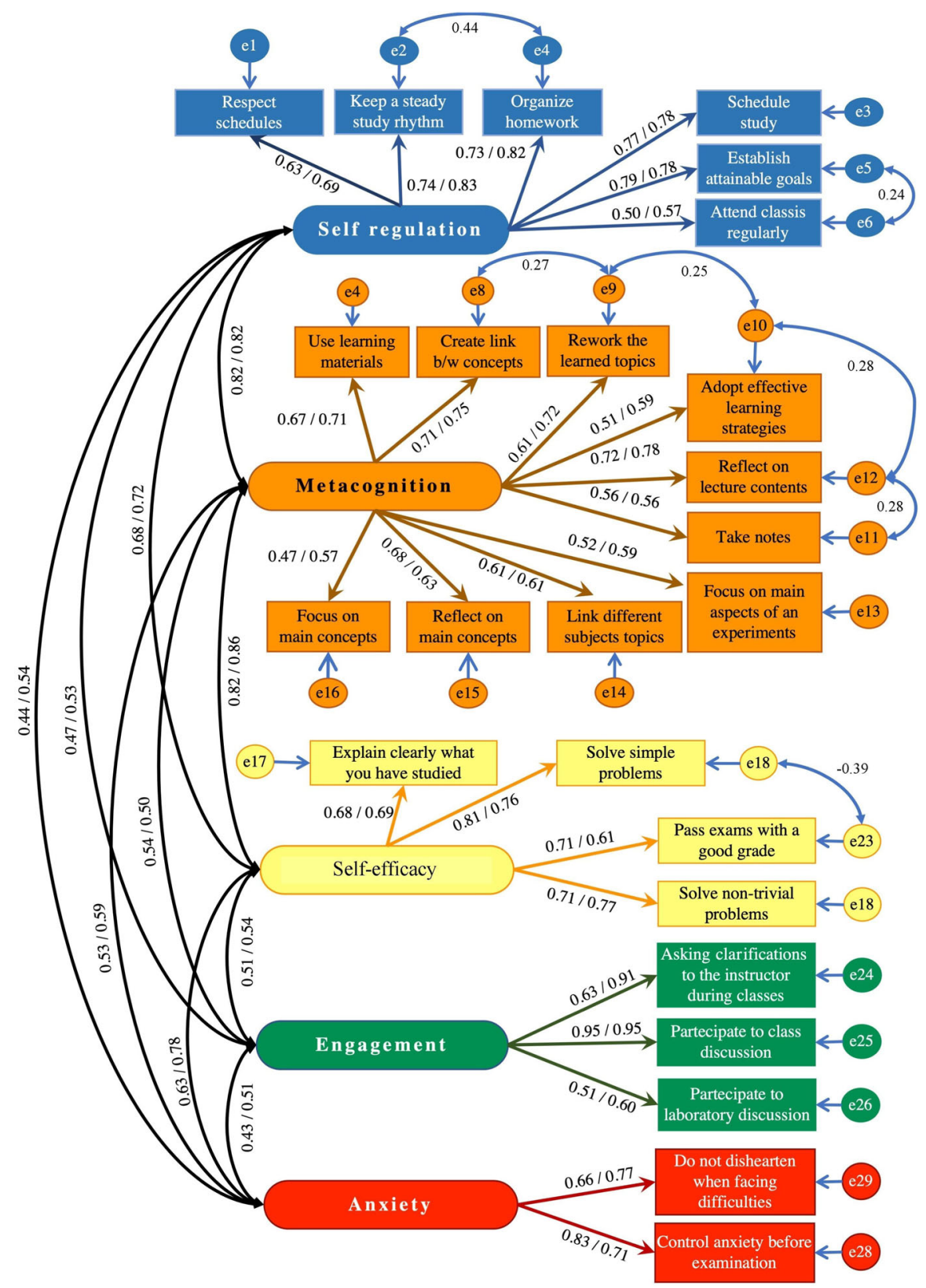

FIG. 5. Factor structure of the physics academic orientation inventory. The unobserved constructs (factors) are represented by rounded rectangles. The observed variables (i.e., the questionnaire items) are represented by rectangles. The single-headed arrows represent structural regression coefficients, namely, the factorial loads of an observed variable onto the factor. The measurement errors associated to observed variables are represented by a circle and a small single-headed arrow near the corresponding variable. Two-headed black arrows represent the covariances of the constructs, while two-headed blue arrows represent the error covariances of the items (modification indices). The values of the loadings between items and constructs and of the covariances between the constructs are reported in the format before and during emergency remote instruction.

RMSEA $=0.046 ;$ after remote instruction: $\chi^{2} /$ d.o.f. $=$ $1.531 ; \mathrm{NFI}=0.988 ; \mathrm{IFI}=0.996 ; \mathrm{CFI}=0.996 ; \mathrm{TLI}=$ 0.992; RMSEA $=0.038$ ).

Figure 4 reports the average raw scores before and after the emergency remote instruction for the three latent dimensions of the motivational construct. We note that emergency remote instruction has negatively affected the motivation towards learning physics. In particular, the average scores decreased significantly in all dimensions $(t>2.501$; d.o.f. $=361 ; p<0.013 ; 0.05<\mathrm{ES}<0.26)$. 


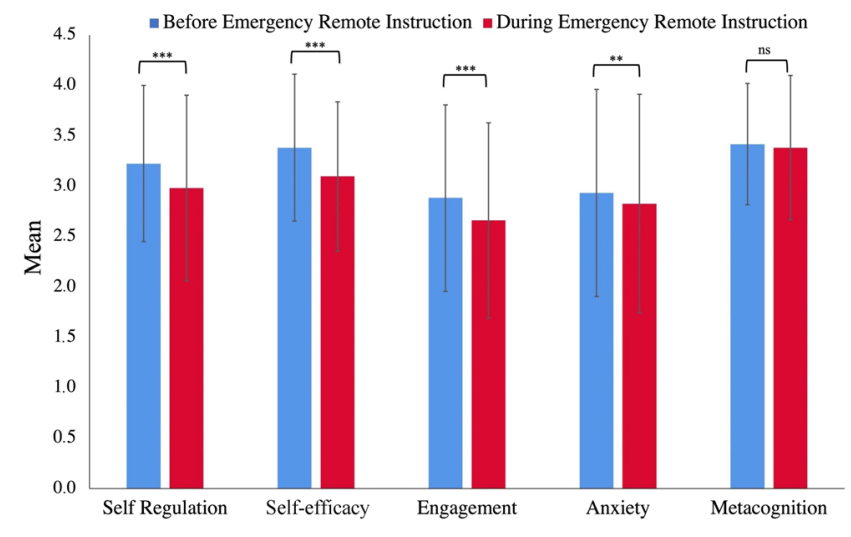

FIG. 6. Mean values of the raw scores of the five latent factors of the PAOI questionnaire before and during emergency remote instruction. Whiskers indicate standard deviation. $* * p<0.01$; $* * * p<0.001 ; \mathrm{ns}=$ nonsignificant. All factors reflect the capability to control a specific aspect of the academic orientation towards physics. For instance, the anxiety factor refers to how well students were able to cope with this emotional state.

\section{How did the emergency remote instruction experience impact on students' academic orientation towards physics?}

We report in Fig. 5 the general factor structure of the PAOI questionnaire. The CFA confirmed the five-factor structure (orientation before remote instruction: $\chi^{2} /$ d.o.f. $=2.031$; $\mathrm{NFI}=0.900 ; \quad \mathrm{IFI}=0.947 ; \quad \mathrm{CFI}=0.946 ; \quad \mathrm{TLI}=0.934$; RMSEA $=0.053$; orientations during remote instruction: $\chi^{2}$ d.o.f. $=2.318 ; \mathrm{NFI}=0.890 ; \mathrm{IFI}=0.934 ; \mathrm{CFI}=0.934 ;$ $\mathrm{TLI}=0.920 ;$ RMSEA $=0.060$ ).

We note that the mean values decreased in all latent dimensions (see Fig. 6) and the differences are significant except in the metacognition dimension $(t>3.105$, d.o.f. $=361, p<0.002,0.10<\mathrm{ES}<0.39$ ).

\section{E. How did the emergency remote instruction experience impact on students' general attitude toward physics and physicists?}

The MCA and CA lead to three stable attitudinal profiles:

1. Accepted discipline (before: $47.2 \%$; after: $49.7 \%$ ). This profile is characterized by a view of physics as an interesting discipline because it intrigues, but also because it is important for the development of society, both from a cultural point of view and for its technological applications.

Society can trust the progress of physics and the contribution of physicists. However, the students in this cluster are not convinced to pursue a future career in physics.

2. Blurred discipline (before: $21.8 \%$; after: $27.9 \%$ ). For students in this cluster, physics has not many tangible effects in everyday life and society. Even in consideration of future developments and employment opportunities, physics seems to be only fairly attractive.

This profile is also characterized by a wary view of physicists, with an unclear role played by physics in the society.

3. Niche discipline (before: $30.9 \%$; after: $22.4 \%$ ). This cluster is characterized by extremely positive views about physics and physicists.

Physics and the work of physicists are considered a fundamental resource for personal life and society. Physics is neither complicated nor abstract; on the contrary, its importance lies in both the theoretical aspects and the technological applications. Hence, it influences our daily life and is therefore necessary to know it.

A career in physics is what students in this cluster are looking for. Students in this profile substantially agree with an elitist view of physics and physicists. The flow of profiles' changes before and after the emergency remote instruction is shown in Fig. 7. We note that the great majority of students in the accepted discipline $(84.8 \%)$ and blurred discipline $(94.9 \%)$ profiles did not substantially change their attitude.

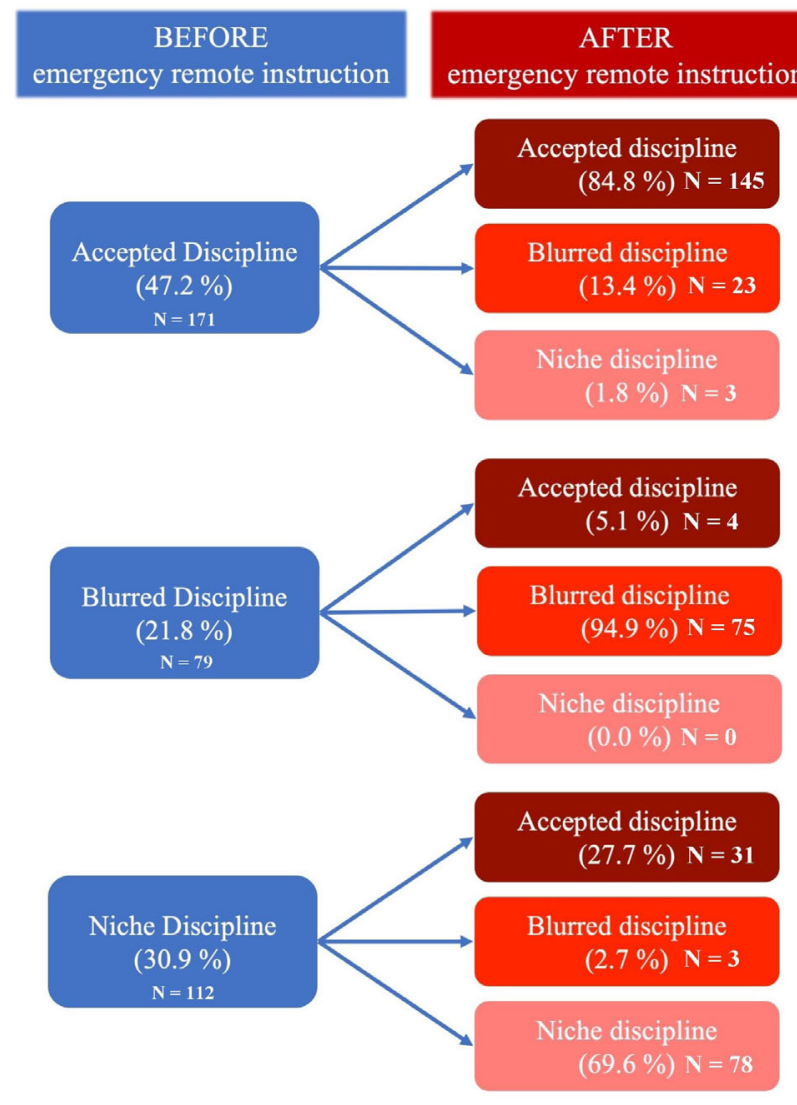

FIG. 7. Changes in attitudes toward physics before and after the emergency remote instruction. 
Differently, about $28 \%$ of the students, initially in the niche discipline profile, changed their attitude, becoming more aligned to the accepted discipline profile.

Overall, the changes amongst the profiles before and after emergency remote instruction are statistically significant $($ McNemar-Bowker test $=193.215, p<0.001)$.

F. How are the changes in the general attitude toward physics, if any, related to students' perception of the emergency remote instruction, and to changes in (a) subjective well being; (b) motivation to learn physics; (c) orientation towards physics?

\section{Changes in the general attitude toward physics}

Changes in attitudinal profiles were grouped in four categories: remain in the accepted discipline (40.1\%), remain in the blurred discipline $(21.8 \%)$, remain in the niche discipline (22.4\%), and worsen the attitude (15.7\%). The latter category includes those students who moved from the accepted discipline profile to the blurred discipline profile and those students who moved from the niche discipline to other profiles. Note also that we included in the remain in the accepted discipline category the few students (4) who moved from the blurred discipline profile to the accepted discipline profile and in the remain in the niche discipline category the students (3) who moved from the accepted discipline profile to the niche discipline profile. Then, since it was the most frequent category, we defined three dummy variables using remain in the accepted discipline as baseline. We finally inserted the three dummy variables in a regression analysis, using as dependent variables the three dimensions of the perception of emergency remote instruction. Results are reported in Table III. We note that to remain in the blurred discipline vs to remain in the accepted discipline is a significant predictor for all the three latent dimensions, in particular for the perception of the effectiveness and organization of the courses. In other words, to remain not interested towards physics and skeptical about the role of physicists in society has lowered the perception of the overall online experience. Contrarily, a downgraded attitude toward physics and physicists has not affected the overall perception of the emergency remote instruction experience. Interestingly, to maintain an elitist view of physics and physicists (niche discipline profile) contributed to lower the perception of the relationship with the instructors during the online experience.

\section{Changes in the general attitude toward physics and SWB}

The distribution of the changes in the attitude towards physics and SWB is shown in Fig. 8. The association is not statistically significant $\left(\chi^{2}=11.147\right.$; d.o.f. $=6$; $p=0.084)$. However, it is interesting to note that onethird of the students, who worsen their attitude toward physics, felt negatively affected by the emergency remote instruction experience, while this is the case for only $14.5 \%$ of the students who remained in the accepted discipline profile, and about one fourth of the students who remained in the niche and blurred discipline profiles.

\section{Changes in the general attitude toward physics and motivation to learn physics}

In Fig. 9 we report the mean of the differences between the interest, utility value, and recognition raw scores after and before the remote distance instruction across the four categories of the change in the attitude towards physics. The differences are statistically significant only in the interest dimension $(F=5.808 ; \quad$ d.o.f. $=3, \quad 358 ; \quad p=0.001$; $\left.\eta^{2}=0.046\right)$ but neither in the utility value dimension (Welch's $F=2.386$; d.o.f. $=3,143.220 ; p=0.072$ ) nor

TABLE III. Linear model of predictors of three latent dimensions of the perception of emergency remote instruction construct.

\begin{tabular}{|c|c|c|c|c|c|}
\hline Dependent variable & $\begin{array}{l}\text { Predictors } \\
\text { (all vs remain in the accepted discipline) }\end{array}$ & $\mathrm{b}$ & SE & $\beta$ & $\mathrm{p}$ \\
\hline \multirow[t]{4}{*}{ Effectiveness and organization of the courses ${ }^{\mathrm{a}}$} & Constant & 3.628 & 0.074 & .. & $<0.001$ \\
\hline & Remain in the blurred discipline & -0.444 & 0.124 & -0.203 & $<0.001$ \\
\hline & Remain in the niche discipline & -0.004 & 0.123 & -0.002 & 0.973 \\
\hline & Worsen the attitude & -0.189 & 0.139 & -0.076 & 0.175 \\
\hline \multirow[t]{4}{*}{ Perceived difficulties ${ }^{\mathrm{b}}$} & Constant & 2.961 & 0.056 & $\ldots$ & $<0.001$ \\
\hline & Remain in the blurred discipline & -0.187 & 0.094 & -0.114 & 0.048 \\
\hline & Remain in the niche discipline & 0.011 & 0.093 & 0.007 & 0.903 \\
\hline & Worsen the attitude & -0.189 & 0.105 & -0.102 & 0.073 \\
\hline \multirow[t]{4}{*}{ Relationship with the instructors ${ }^{c}$} & Constant & 3.088 & 0.063 & $\cdots$ & $<0.001$ \\
\hline & Remain in the blurred discipline & -0.288 & 0.106 & -0.156 & 0.007 \\
\hline & Remain in the niche discipline & -0.212 & 0.105 & -0.115 & 0.045 \\
\hline & Worsen the attitude & -0.197 & 0.119 & -0.094 & 0.098 \\
\hline
\end{tabular}

\footnotetext{
${ }^{\mathrm{a}} \mathrm{R}^{2}=0.040$

${ }^{\mathrm{b}} \mathrm{R}^{2}=0.019$.

${ }^{\mathrm{c}} \mathrm{R}^{2}=0.024$.
} 


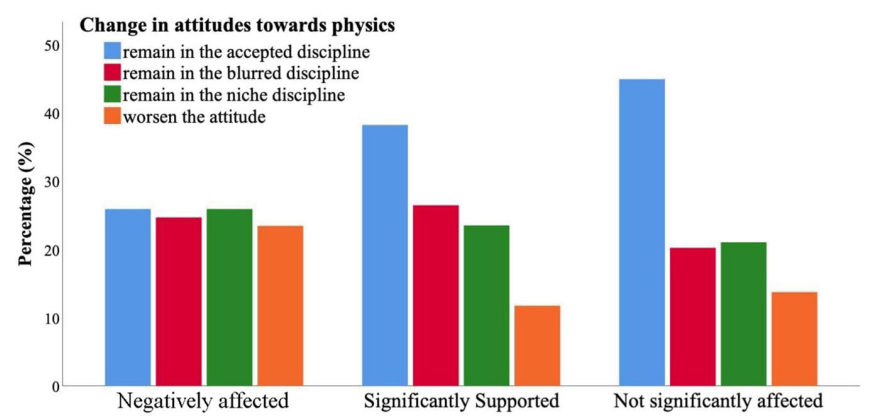

FIG. 8. Distribution of the changes in the attitude toward physics across the SWB clusters. The percentages sum up to $100 \%$ for each cluster.

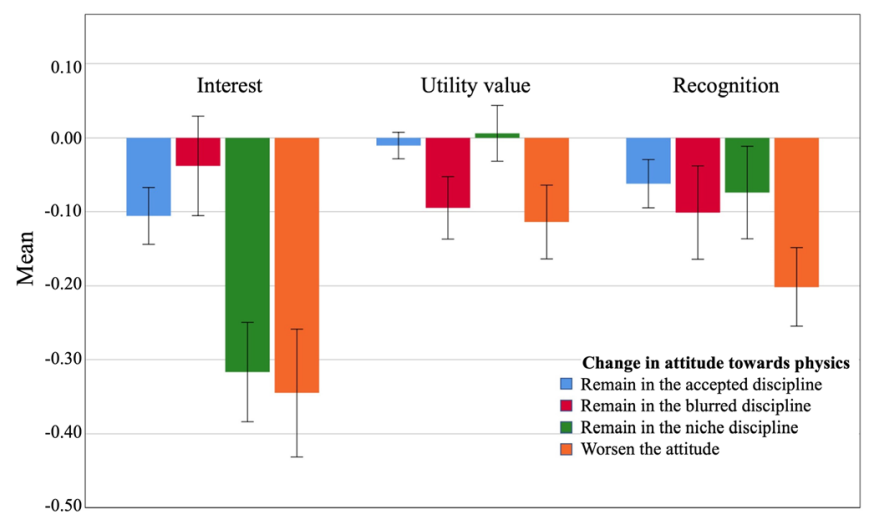

FIG. 9. Mean of the differences between the interest, utility value, and recognition raw scores after and before the remote distance instruction across the four categories of change in the attitude towards physics. Whiskers indicate standard deviation.

in the recognition dimension $(F=1.236$; d.o.f. $=3,358$; $p=0.296)$. We note that for the interest dimension, the scores after the remote distance instruction are significantly lower for the remain in the niche discipline and for the worsen the attitude categories $(t=-4.164$, d.o.f. $=358$, $p<0.001, \mathrm{ES}=0.46)$ in comparison to the other two categories. While differences across the groups are not significant, it is worth reporting that the utility value scores after remote distance instruction are significantly lower for the remain in the blurred discipline and for the worsen the attitude categories in comparison to the other two groups $(t=-2.633$; d.o.f. $=203.645 ; p=0.009 ; \mathrm{ES}=0.34)$.

\section{Changes in the general attitude toward physics and academic orientation towards physics}

When analyzing the scores for the academic orientation towards physics (Fig. 10), we note that the differences across the groups are statistically significant for all dimensions (Welch's $F_{\text {self-regulation }}=3.539$, d.o.f. $=3,152.462 ; p=$ $0.016 ; F_{\text {self-efficacy }}=3.388$; d.o.f. $=3,358 ; p=0.023$;

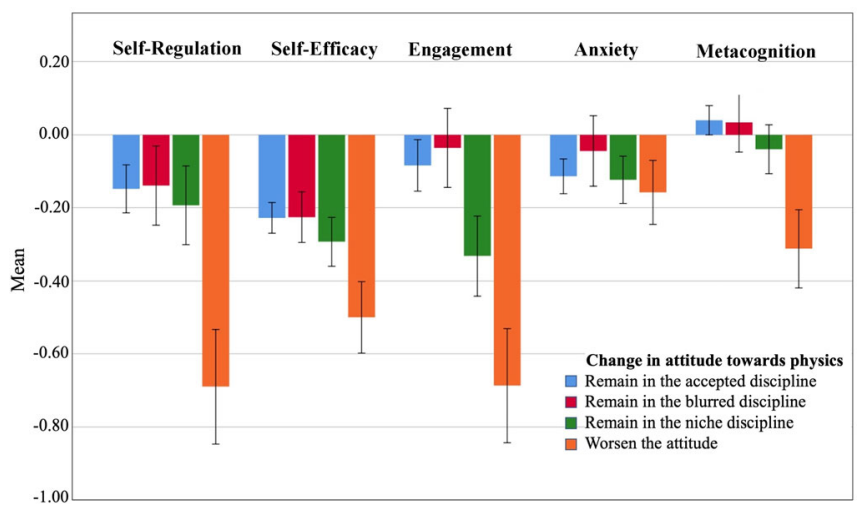

FIG. 10. Mean of the differences for the academic orientation towards physics raw scores across the four categories of change in the attitude towards physics. Whiskers indicate standard deviation.

Welch's $\quad F_{\text {engagement }}=5.325, \quad$ d.o.f. $=3, \quad 154.999 ; \quad p=$ 0.002 ; Welch's $F_{\text {metacognition }}=3.317$; d.o.f. $=3,148.257$, $p=0.022) \quad$ except anxiety $(F=0.370 ; \quad$ d.o.f. $=3$; $p=0.774)$. We also note that, for all dimensions except anxiety, differences between pre and post remote instruction academic orientation perceptions are significantly lower for the worsen the attitude group $(t>-2.989$, d.o.f. $=358$, $p<0.004,0.32<\mathrm{ES}<0.52)$.

\section{DISCUSSION}

The main aim of this paper was to give a contribution toward a more thorough understanding of the aspects that most affected the students' experience of the emergency remote instruction. Overall, we found a positive view of the effectiveness and organization of the online courses. This means that students in our sample think that Italian university physics courses, on average, managed in an appropriate way the sudden and unexpected transition towards the remote teaching. However, as for many of the policy measures enacted by Italy government to face the outbreak of COVID-19 [99], such transition was not smooth. Actually, we detected significant difficulties in several aspects of the online experience, such as the relationships with peers or the perceived diminished preparation in physics.

The relationships with instructors were judged as worsened with respect to the in-person activities, but not significantly, as found in other disciplines and countries [16]. While this is an encouraging result, it also suggests some considerations on the use of online tools by university instructors. Indeed, most of the open-ended responses given by the students questioned the pedagogical approach used during the online sessions, and not the clarity in the explanation. The use of slides and predefined documents was seen negatively by the students, as well as the adoption of the lecture format. In many cases, the students justify 
such claims by saying that slide presentation in a lecture format increases the workload with respect to the in-person teaching and reduces the interaction not only with the instructor but also among peers.

Concerning the subjective well being, despite the scores in all the descriptors showed a significant decrease, only about $20 \%$ of the students in the sample felt negatively affected by the emergency remote instruction. In particular, this cluster is characterized by being sadder and more stressed and, at the same time, definitely less satisfied, enthusiastic, energetic, stimulated, optimistic, and happy. Most of these items correspond to mood states traditionally associated with pleasant or highly positive affects. Thus, a significant decrease in the students' perception about these items signals a general dimension of subjective distress likely due to the remote distance instruction, since the students in this cluster had the lowest scores in the three latent dimensions of the emergency remote instruction perception. Our result is in contrast with other studies in psychology education [17,28], which report higher percentages of university students who were negatively impacted by online teaching. However, we note that these previous studies involved a broader population of students. We also note that about $70 \%$ of the students of our sample felt not significantly affected by the emergency remote instruction experience. This result may be explained taking into account the personal strategies enacted by the students to cope with the psychological distress due to the online teaching, as suggested by prior studies with undergraduate students in Europe [100]. However, more research is warranted to investigate specific aspects of these strategies and their relationships with the remote learning experience in physics.

While the decrease of motivation has been reported in prior studies [17], to our knowledge, this paper is the first study that investigated changes in academic motivation. We found that the online experience affected all the motivational dimensions and, in particular, the interest and the recognition by peers and professors. From the open responses, we infer that this result may be linked to the loss of engagement with peers, the scarce attractiveness of online lectures, and the absence of practical sessions, which are critical for physics [101]. However, more research is needed to understand in more detail why motivation towards physics decreased in such a significant manner.

The emergency remote instruction has also significantly affected four dimensions of students perceived orientation towards physics (self-regulation, self-efficacy, engagement, and anxiety), while metacognition seems to have not been affected. Such result has also been found in a previous study with U.S. students [28]. A possible interpretation, for such result in our sample, is the following: self-regulation and mastery are capabilities that were deeply challenged by remote instruction. Online courses were perceived as denser from the content viewpoint and, because of the exam modalities (see context information in Sec. II B), as more demanding, given the difficulty in remaining focused on a screen for a long time. The decrease in the engagement dimension can be related to perceived loneliness during online lectures, which often did not favor peers' interaction, while the decrease in the capability to control anxiety may be linked to increased psychological stress and decreased extraversion, well documented in prior studies [102]. Interestingly, metacognition, which refers to the ability to control one's own learning or problem-solving activities, was not significantly affected. Our interpretation is that emergency remote instruction did not require students to significantly change their own learning strategies. However, we do not have enough evidence about the impact of remote distance teaching on, for instance, the number of classes attended during the lockdown or the number of delayed exams. Furthermore, the effects of remote instruction on orientation towards physics may also depend on other factors, such as gender and age. All these aspects are the subject of an ongoing study, focused on the academic performance of physics students during online instruction.

Finally, in contrast with a recent study [103], which found that the university students' views about experimental physics did not significantly decrease after the online teaching transition with respect to earlier pre-COVID-19 surveys, our data support a significant change in the attitudes towards physics, especially for those students who expressed extremely positive attitudes towards physics (niche discipline) before the emergency remote instruction. A particularly worrying signal is that, while remaining substantially interested in physics, these students became less positive toward a possible career in physics. In particular, from the regression analysis, we can infer that a less positive attitude toward physics is related to an increase in the perceived difficulty in attaining their university degree and in finding job opportunities. Such feeling of uncertainty for the future can be conceptualized by the fear of academic year loss construct, introduced in a recent study with Bangladeshi college students [104]. While the fear of academic year loss may impact the students' subjective well being, our results do not support the general conclusion that the attitude towards the discipline was negatively affected by the psychological discomfort while attending the online courses. Differently, such changes were likely related to more specific difficulties perceived during the emergency remote instruction. For instance, the physical distance from the cultural context of the university may have negatively affected how students perceive the value of their chosen degree discipline. As one student in the niche discipline profile claimed: "I came here at university to attend in-person lessons delivered by great professors in presence. If I wanted to see them on a screen, I would have enrolled in an online university." Our interpretation is supported by the finding that a very positive attitude toward physics before going online is 
associated to a less favorable judgment of the relationship with instructors during the online courses. As discussed above, the latter result may be explained by the negative perception of the slide-based lecturing approach during online classes and by the disappointment for the limited interaction with the instructor. However, also in light of the results reported in Ref. [103], more research is needed to inspect whether such negative perceptions concerned also online virtual laboratory sessions or were limited to lectures.

\section{LIMITATIONS}

Our study has five main limitations.

First, we involved a convenience sample recruited online that represents only a limited group of students, although distributed across the whole country. Inference outside our population requires a cross-sectional research with a more adequate sampling design.

Second, we used only self-reported measures with no prior or longitudinal data for comparison with the measurements of the observed variables. For instance, it could be that students' attitudes may also decline with regular instruction. While we believe that the use of the retrospective pretest-post-test methodology is able to reliably detect changes related to a specific event (such as the COVID-19 pandemic), we plan to compare changes in the measured variables with a different cohort of physics students during a regular semester in order to validate the findings obtained for the emergency remote instruction.

Third, we surveyed students during the so-called secondwave of COVID-19 pandemic during October-December 2020. Hence, students' responses could have been biased by the on-going situation that was perceived by the Italian general public as even more disruptive than the first lockdown in spring 2020.

Fourth, the rate of response was about $30 \%$. Hence, our results may be biased by self-selection of the respondents. In particular, the high percentage of students expressing difficulties with instructors may be related to this bias. A more adequate sampling, coupled with a series of interviews, may help understand the extent to which such bias has affected our study.

Finally, the questionnaire was submitted online, thus potentially limiting the participation in the study of those students without a reliable internet access and personal electronic devices (computer, tablet, ...).

\section{CONCLUSIONS}

The main conclusion of our study is that the organization of the emergency remote instruction by Italian university physics courses was positively perceived by the students. Another important point is that the great majority of the involved students did not feel psychologically affected by the online teaching modality. However, these findings by no means should be interpreted in that remote instruction is better than in-person instruction. Actually, about two-thirds of the students still prefer in-person activities. Hence, our results only suggest that students have accepted the emergency remote instruction as a desperate, but temporary measure to cope with the pandemic. Moreover, far from being flawless, the transition had the consequence that the students become more concerned about their future and less favorable toward how their instructors enacted the online teaching. Furthermore, the transition has also negatively impacted on students' motivation, academic orientation, and attitude towards physics. While changes in attitudes towards physics predicted in part the overall perception of the remote learning experience, more research is needed to investigate in more detail how changes in motivation and self-efficacy affected such perception. Recent studies have proposed a number of practices to better support students during the online instruction [16]. To propose strategies specific to online teaching for physics is beyond the scope of this paper. However, our study may be a useful basis on which to design approaches more responsive to students' needs and difficulties. In conclusion, as countries worldwide implement strategies to control the COVID-19 pandemic, different options are still on the table regarding university instruction. While we are writing the first draft of this manuscript, we are facing in Italy a third-wave of COVID-19 contagions, which is leading to a further closure of universities in the entire country. Our findings, presenting how emergency remote instruction impacted affective and motivational dimensions of university physics students, may help predict the effects of closures that remain the only option before the vaccination campaign has reached a significant portion of the population. Although, at first sight, our results suggest that the impact was limited after the first lockdown, recent studies [105] suggest that the longer the closures continue the more the students' perceptions may worsen, as their families keep on struggling with deteriorating economic conditions. Hence, students, specially freshmen, may be in need of a greater institutional support. Such support should not be limited to safety protocols or improved online teaching but it should also include specific interventions on affective and motivational aspects.

\section{ACKNOWLEDGMENTS}

The authors are deeply grateful to the students who answered the questionnaire during such a difficult time. This study has partly received funds from the Italian Ministry of University and Research Project: "Piano Nazionale Lauree Scientifiche". 
[1] World Health Organization, Coronavirus disease 2019, https://www.who.int/emergencies/diseases/novelcoronavirus-2019 (2019), accessed Mar 18, 2021.

[2] Y.-C. Wu, C.-S. Chen, and Y.-J. Chan, The outbreak of COVID-19: An overview, J. Chin. Med. Assoc. 83, 217 (2020).

[3] M. L. Holshue et al., First case of 2019 novel coronavirus in the United States, New Engl. J. Med. 382, 929 (2020).

[4] E. Levenson, C. Boyette, and J. Mack, Colleges and universities across the U.S. are canceling in-person classes due to coronavirus, https://edition.cnn.com/ 2020/03/09/us/coronavirus-university-college-classes/ index.html (2020), accessed Mar 18, 2021.

[5] K. Adams, UK universities switching to online lectures and exams, https://www.theguardian.com/world/2020/ mar/12/uk-universities-switching-to-online-lectures-andexams (2020), accessed Mar 18, 2021.

[6] D. De Alwis, S. K. Saif, and S. Niazi, Universities shut down across south and southeast Asia, https://www .universityworldnews.com/post.php?

story $=2020032008521144$ (2020), accessed Mar 18, 2021.

[7] W. Zhang, Y. Wang, L. Yang, and C. Wang, Suspending classes without stopping learning: China's education emergency management policy in the COVID-19 outbreak, J. Risk Financial Manag. 13, 55 (2020).

[8] W. Bao, COVID-19 and online teaching in higher education: A case study of Peking University, Hum. Behav. Emerg. Tech. 2, 113 (2020).

[9] C. Hodges, S. Moore, B. Lockee, T. Trust, and M. A. Bond, The difference between emergency remote teaching and online learning, https://er.educause.edu/articles/ 2020/3/the-difference-between-emergency-remoteteaching-and-online-learning (2020), accessed Mar 18, 2021.

[10] A. Aristovnik, D. Keržič, D. Ravšelj, N. Tomaževič, and L. Umek, Impacts of the COVID-19 pandemic on life of higher education students: A global perspective, Sustainability 12, 34 (2020).

[11] V. Gjerde, R. Gray, B. Holst, and S. Kolstø, The Covid-19 shutdown: When studying turns digital, students want more structure, Phys. Educ. 56, 055004 (2021).

[12] T. A. Holme, Introduction to the journal of chemical education special issue on insights gained while teaching chemistry in the time of COVID-19, J. Chem. Educ. 97, 2375 (2020).

[13] E. G. Campari, M. Barbetta, S. Braibant, N. Cuzzuol, A. Gesuato, L. Maggiore, F. Marulli, G. Venturoli, and C. Vignali, Physics laboratory at home during the COVID19 pandemic, Phys. Teach. 59, 68 (2021).

[14] M. Carli, M. R. Fontolan, and O. Pantano, Teaching optics as inquiry under lockdown: How we transformed a teaching-learning sequence from face-to-face to distance teaching, Phys. Educ. 56, 025010 (2021).

[15] P. Klein, L. Ivanjek, M. N. Dahlkemper, K. Jelicic, G. M.-A., S. Kuchemann, and S. A., Studying physics during the covid-19 pandemic: Student assessments of learning achievement, perceived effectiveness of online recitations, and online laboratories, Phys. Rev. Phys. Educ. Res. 17, 010117 (2021).

[16] R. J. Petillion and W. S. McNeil, Student experiences of emergency remote teaching: Impacts of instructor practice on student learning, engagement, and well-being, J. Chem. Educ. 97, 2486 (2020).

[17] M. H. E. M. Browning, L. R. Larson, I. Sharaievska, A. Rigolon, O. McAnirlin, L. Mullenbach, S. Cloutier, T. M. $\mathrm{Vu}$, J. Thomsen, N. Reigner, E. C. Metcalf, A. D'Antonio, M. Helbich, G. N. Bratman, and H. O. Alvarez, Psychological impacts from COVID-19 among university students: Risk factors across seven states in the United States, PLoS One 16, 1 (2021).

[18] S. Sankhi and N. R. Marasine, Impact of COVID-19 pandemic on mental health of the general population, students, and health care workers, Eur. J. Med. Sci. 2, 82 (2020).

[19] C. Son, S. Hegde, A. Smith, X. Wang, and F. Sasangohar, Effects of COVID-19 on college students' mental health in the United States: Interview survey study, J. Med. Internet Res. 22, e21279 (2020).

[20] W. Cao, Z. Fang, G. Hou, M. Han, X. Xu, J. Dong, and J. Zheng, The psychological impact of the COVID-19 epidemic on college students in China, Psychiatry Res. 287, 112934 (2020).

[21] M. A. Islam, S. D. Barna, H. Raihan, M. N. A. Khan, and M. T. Hossain, Depression and anxiety among university students during the COVID-19 pandemic in Bangladesh: A web-based cross-sectional survey, PLoS One 15, 1 (2020).

[22] A. Essadek and T. Rabeyron, Mental health of French students during the Covid-19 pandemic, J. Aect. Disord. 277, 392 (2020).

[23] C. K. Kaparounaki, M. E. Patsali, D.-P. V. Mousa, E. V. K. Papadopoulou, K. K. K. Papadopoulou, and K. N. Fountoulakis, University students' mental health amidst the COVID-19 quarantine in Greece, Psychiatry Res. 290, 113111 (2020).

[24] P. Odriozola-González, Á. Planchuelo-Gómez, M. J. Irurtia, and R. de Luis-García, Psychological effects of the COVID-19 outbreak and lockdown among students and workers of a Spanish university, Psychiatry Res. 290, 113108 (2020).

[25] M. M. Husky, V. Kovess-Masfety, and J. D. Swendsen, Stress and anxiety among university students in France during covid-19 mandatory confinement, Comprehensive psychiatry 102, 152191 (2020).

[26] N. Meda, S. Pardini, I. Slongo, L. Bodini, M. A. Zordan, P. Rigobello, F. Visioli, and C. Novara, Students' mental health problems before, during, and after COVID-19 lockdown in Italy, Journal of psychiatric research 134, 69 (2021).

[27] A. Bozkurt and R. C. Sharma, Emergency remote teaching in a time of global crisis due to coronavirus pandemic, Asian J. Distance Educ. 15, 1 (2020), http://www.asianjde .org/ojs/index.php/AsianJDE/article/view/447url.

[28] A. Patricia Aguilera-Hermida, College students' use and acceptance of emergency online learning due to COVID19, Int. J. Educ. Res. Open 1, 100011 (2020). 
[29] T. D. Little, R. Chang, B. K. Gorrall, L. Waggenspack, E. Fukuda, P. J. Allen, and G. G. Noam, The retrospective pretest-posttest design redux: On its validity as an alternative to traditional pretest-posttest measurement, Int. J. Behav. Dev. 44, 175 (2020).

[30] See Supplemental Material at http://link.aps.org/ supplemental/10.1103/PhysRevPhysEducRes.17.020130 for instruments and statistics for the measured variables.

[31] P. Chakraborty, P. Mittal, M. S. Gupta, S. Yadav, and A. Arora, Opinion of students on online education during the COVID-19 pandemic, Hum. Behav. Emerg. Tech. 3, 357 (2021).

[32] D. Watson, L. A. Clark, and A. Tellegen, Development and validation of brief measures of positive and negative affect: The PANAS scales, J. Pers. Soc. Psychol. 54, 1063 (1988).

[33] E. R. Thompson, Development and validation of an internationally reliable short-form of the positive and negative affect schedule (PANAS), J. Cross-Cult. Psychol. 38, 227 (2007).

[34] J. Brophy, Motivating Students to Learn, 2nd ed. (Lawrence Erlbaum, Hillsdale, NJ, 2004).

[35] F. Alivernini, F. Lucidi, and S. Manganelli, The assessment of academic motivation: A mixed methods study, Int. J. Mult. Res. Approaches 2, 71 (2008).

[36] S. M. Glynn, G. Taasoobshirazi, and P. Brickman, Science motivation questionnaire: Construct validation with nonscience majors, J. Res. Sci. Teach. 46, 127 (2009).

[37] S. Glynn and T. J. Koballa, Motivation to learn college science, in Handbook of College Science Teaching, edited by J. J. Mintzes and W. H. Leonard (National Science Teachers Association Press, Arlington, VA, 2006).

[38] R. J. Vallerand, L. G. Pelletier, M. R. Blais, N. M. Briere, C. Senecal, and E.F. Vallieres, On the assessment of intrinsic, extrinsic, and amotivation in education: Evidence on the concurrent and construct validity of the academic motivation scale, Educ. Psychol. Meas. 53, 159 (1993).

[39] W. K. Adams, K. K. Perkins, N. S. Podolefsky, M. Dubson, N. D. Finkelstein, and C. E. Wieman, New instrument for measuring student beliefs about physics and learning physics: The Colorado learning attitudes about science survey, Phys. Rev. ST Phys. Educ. Res. 2, 010101 (2006)

[40] M. M. Bleeker and J. E. Jacobs, Achievement in math and science: Do mothers' beliefs matter 12 years later?, J. Educ. Psychol. 96, 97 (2004).

[41] J. E. Jacobs and J.S. Eccles, The impact of mothers' gender-role stereotypic beliefs on mothers' and children's ability perceptions, J. Pers. Soc. Psychol. 63, 932 (1992).

[42] J. E. Jacobs and J. S. Eccles, Parents, task values, and reallife achievement-related choices, in Intrinsic and Extrinsic Motivation, edited by C. Sansone and J. M. Harackiewicz (Academic Press, San Diego, 2000), pp. 405-439.

[43] Z. Hazari, G. Sonnert, P. M. Sadler, and M.-C. Shanahan, Connecting high school physics experiences, outcome expectations, physics identity, and physics career choice: A gender study, J. Res. Sci. Teach. 47, 978 (2010).

[44] Z. Hazari, D. Chari, G. Potvin, and E. Brewe, The context dependence of physics identity: Examining the role of performance/competence, recognition, interest, and sense of belonging for lower and upper female physics undergraduates, J. Res. Sci. Teach. 57, 1583 (2020).

[45] P. L. Gardner and P. Tamir, Interest in biology. Part I: A multidimensional construct, J. Res. Sci. Teach. 26, 409 (1989).

[46] K. A. Renninger, Interest and identity development in instruction: An inductive model, Educ. Psychol. 44, 105 (2009).

[47] S. Hidi and K. A. Renninger, The four-phase model of interest development, Educ. Psychol. 41, 111 (2006).

[48] R. M. Ryan and E. L. Deci, Self-determination theory and the facilitation of intrinsic motivation, social development, and well-being, Am. Psychol. 55, 68 (2000).

[49] J. Eccles, T. Adler, R. Futterman, S. Goff, C. Kaczala, J. Meece, and C. Midgley, Expectancies, values, and academic behaviours, in Achievement and Achievement Motivation, edited by J. T. Spence (W. H. Freeman, San Francisco, 1983), pp. 75-146.

[50] A. Wigfield and J. S. Eccles, Expectancy-value theory of achievement motivation, Contemp. Educ. Psychol. 25, 68 (2000).

[51] J. Eccles, B. Barber, and D. Jozefowicz, Linking gender to education, occupation, and recreational choices: Applying the Eccles et al. model of achievement-related choices (American Psychological Association, Washington, DC, 1999), pp. 153-192.

[52] M. V. Bøe and E. K. Henriksen, Love it or leave it: Norwegian students' motivations and expectations for postcompulsory physics, Sci. Educ. 97, 550 (2013).

[53] Metacognition in Learning and Instruction, 1st ed., Neuropsychology and Cognition, edited by H. J. Hartman (Springer, Netherlands, 2001), Vol. 19, https://www .springer.com/gp/book/9780792368380.

[54] D. H. Schunk and M. K. DiBenedetto, Self-efficacy and human motivation, in Advances in Motivation Science, edited by A. J. Elliot (Elsevier, New York, 2021), Vol. 8, pp. 153-179, https://doi.org/10.1016/bs.adms.2020 .10 .001 .

[55] A. Ben-Eliyahu, D. Moore, R. Dorph, and C. D. Schunn, Investigating the multidimensionality of engagement: Affective, behavioral, and cognitive engagement across science activities and contexts, Contemp. Educ. Psychol. 53, 87 (2018).

[56] R. Cera, M. Mancini, and A. Antonietti, Relationships between metacognition, self-efficacy and self-regulation in learning, J. Educ. Cultural Psychol. Studies 4, 115 (2013).

[57] S. Manganelli, F. Alivernini, L. Mallia, and V. Biasi, The development and psychometric properties of the "selfregulated knowledge scale-university" (srks-u), J. Educ. Cultural Psychol. Studies 1, 235 (2015).

[58] G. Thomas, D. Anderson, and S. Nashon, Development of an instrument designed to investigate elements of science students' metacognition, self-efficacy and learning processes: The semli-s, Int. J. Sci. Educ. 30, 1701 (2008)

[59] G. Taasoobshirazi, M. Bailey, and J. Farley, Physics metacognition inventory Part II: Confirmatory factor 
analysis and Rasch analysis, Int. J. Sci. Educ. 37, 2769 (2015).

[60] A. Gungor and M. De Cock, Validity of the physics affective characteristics scale for Flemish pharmacy and biology majors, Phys. Rev. Phys. Educ. Res. 17, 010132 (2021).

[61] L. Anthonysamy, A.-C. Koo, and S.-H. Hew, Selfregulated learning strategies and non-academic outcomes in higher education blended learning environments: A one decade review, Educ. Inf. Technol. 25, 3677 (2020).

[62] L. Barnard, W. Y. Lan, Y. To, V. O. Paton, and S.-L. Lai, Measuring self-regulation in online and blended learning environments, Internet Higher Educ. 12, 1 (2009).

[63] Z. D. Kirbulut and E. Uzuntiryaki-Kondakci, Examining the mediating effect of science self-efficacy on the relationship between metavariables and science achievement, Int. J. Sci. Educ. 41, 995 (2019).

[64] D. Akamatsu, M. Nakaya, and R. Koizumi, Effects of metacognitive strategies on the self-regulated learning process: The mediating effects of self-efficacy, Behav. Sci. 9, 128 (2019).

[65] Z. Khlaif, S. Salha, and B. Kouraichi, Emergency remote learning during covid-19 crisis: Students' engagement, Educ. Inf. Technol., https://doi.org/10.1007/s10639-02110566-4 (2021).

[66] H. Y. Li, H. Cao, D. Y. P. Leung, and Y. W. Mak, The psychological impacts of a COVID-19 outbreak on college students in china: A longitudinal study, Int. J. Environ. Res. Public Health 17, 3933 (2020).

[67] C. Wang, R. Pan, X. Wan, Y. Tan, L. Xu, C. S. Ho, and R. C. Ho, Immediate psychological responses and associated factors during the initial stage of the 2019 coronavirus disease (COVID-19) epidemic among the general population in china, Int. J. Environ. Res. Public Health 17, 1729 (2020).

[68] K. Tzafilkou, M. Perifanou, and A. Economides, Negative emotions, cognitive load, acceptance, and self-perceived learning outcome in emergency remote education during COVID-19, Educ. Inf. Technol., https:// doi.org/10.1007/s10639-021-10604-1 (2021).

[69] B. J. Zimmerman, Investigating self-regulation and motivation: Historical background, methodological developments, and future prospects, Am. Educ. Res. J. 45, 166 (2008).

[70] J. Flavell, Cognitive development: Past, present, and future, Dev. Psychol. 28, 998 (1992).

[71] M. V. J. Veenman, B. H. A. M. Van Hout-Wolters, and P. Afflerbach, Metacognition and learning: Conceptual and methodological considerations, Metacogn. Learn. 1, 3 (2006).

[72] A. Bandura, Self-efficacy: Toward a unifying theory of behavioral change, Psychol. Rev. 84, 191 (1977).

[73] Bandura, Self-Efficacy: The Exercise of Control (W H Freeman/Times Books/ Henry Holt \& Co, New York, 1997).

[74] E. L. Usher and F. Pajares, Sources of self-efficacy in mathematics: A validation study, Contemp. Educ. Psychol. 34, 89 (2009).
[75] G. Esposito, J. Marôco, R. Passeggia, G. Pepicelli, and M. F. Freda, The Italian validation of the university student engagement inventory, Eur. J. High. Educ. 1 (2021).

[76] M. Udo, G. Ramsey, and J. Mallow, Science anxiety and gender in students taking general education science courses, J. Sci. Educ. Technol. 13, 435 (2004).

[77] P. Kind, K. Jones, and P. Barmby, Developing attitudes towards science measures, Int. J. Sci. Educ. 29, 871 (2007).

[78] S. Salvatore, J. Valsiner, and G. Veltri, The theoretical and methodological framework. Semiotic cultural psychology, symbolic universes and lines of semiotic forces, in Symbolic Universes in Time of (Post)Crisis. Culture in Policy Making: The Symbolic Universes of Social Action, edited by S. Salvatore, V. Fini, T. Mannarini, J. Valsiner, and G. Veltri (Springer, Cham., 2019).

[79] S. Salvatore et al., and on behalf of the Re.Cri.Re. Consortium, Symbolic universes between present and future of Europe, First results of the map of European societies' cultural milieu, PLoS One 13, 1 (2018).

[80] S. Salvatore and M. F. Freda, Affect, unconscious and sensemaking. A psychodynamic, semiotic and dialogic model, New Ideas Psychol. 29, 119 (2011).

[81] I. Testa, R. De Luca Picione, and U. Scotti di Uccio, Patterns of Italian high school and university students' attitudes towards physics: An analysis based on semioticcultural perspective, Eur. J. Psychol. Educ., https:// doi.org/10.1007/s10212-021-00563-z (2021).

[82] P.-T. Oon and R. Subramaniam, Factors influencing Singapore students' choice of physics as a tertiary field of study: A Rasch analysis, Int. J. Sci. Educ. 35, 86 (2013).

[83] K. M. Stokking, Predicting the choice of physics in secondary education, Int. J. Sci. Educ. 22, 1261 (2000).

[84] Anagrafe Nazionale Studenti, https://anagrafe.miur.it/ index.php (2021), accessed Jul 20, 2021.

[85] A. Di Ciaccio, C. La Tessa, S. Pirrone, G. M. Ratto, P. Rossi, and S. Soria, Analisi di genere del profilo dei laureati in fisica italiani, (Italian Physical Society), https://www.sif.it/static/SIF/resources/public/files/ Report-CPO-20190730.pdf (2019).

[86] J. Schreiber, A. Nora, F. Stage, E. Barlow, and J. King, Reporting structural equation modeling and confirmatory factor analysis results: A review, J. Educ. Res. 99, 323 (2006).

[87] P. Kline, The Handbook of Psychological Testing (Routledge, London, 2000).

[88] W. J. Boone, S. J. R., and Y. M. S., Rasch Analysis in the Human Sciences (Springer Netherlands, Dordrecht, 2014).

[89] M. Linacre, Winsteps® Rasch Tutorial 4, http://www .winsteps.com/a/winsteps-tutorial-4.pdf (2012).

[90] H. Abdi and D. Valentin, Multiple correspondence analysis, in Encyclopedia of Measurement and Statistics, edited by N. J. Salkind (SAGE Publications, Inc., Newbury Park, CA, 2007), Vol. 1, pp. 652-657, https://doi.org/10.4135/9781412952644.n299.

[91] J. Blasius and M. Greenacre, in Multiple Correspondence Analysis and Related Methods, edited by G. Michael and 
B. Jorg (Chapman and Hall/CRC, London, 2006), https:// doi.org/10.1201/9781420011319.

[92] F. Husson and J. Josse, Multiple correspondence analysis, in Visualization and Verbalization of Data, edited by J. Blasius and M. Greenacre (Chapman \& Hall/CRC, Boca Raton, 2014), pp. 165-184, https://doi.org/10.1201/b16741.

[93] B. Le Roux and H. Rouanet, Multiple Correspondence Analysis (SAGE Publications, Inc., Newbury Park, CA, 2010), https://doi.org/10.4135/9781412993906.

[94] B. Everitt, S. Landau, M. Leese, and D. Stahl, Cluster Analysis (John Wiley \& Sons, Ltd., New York, 2011), https://doi.org/10.1002/9780470977811.

[95] J. Ott, Analysis of Human Genetic Linkage, The Johns Hopkins series in contemporary medicine and public health (Johns Hopkins University Press, Baltimore, MD, 1999), https://books.google.it/books? $\mathrm{id}=$ plqENXLNANOC.

[96] Cluster Analysis in Neuropsychological Research, Recent Applications, edited by D. Allen and G. Goldstein (Springer-Verlag, New York, 2013), https://doi.org/ 10.1007/978-1-4614-6744-1.

[97] R. N. Mantegna, Hierarchical structure in financial markets, Eur. Phys. J. B 11, 193 (1999).

[98] Statistical Power Analysis for the Behavioral Sciences (Academic Press, New York, 1977), https://doi.org/ 10.1016/C2013-0-10517-X.

[99] G. Capano, Policy design and state capacity in the COVID-19 emergency in Italy: if you are not prepared for the (un)expected, you can be only what you already are, Phys. Scr. 39, 326 (2020).

[100] S. Lischer, N. Safi, and C. Dickson, Remote learning and students' mental health during the covid-19 pandemic: A mixed-method enquiry, PROSPECTS, https://doi.org/ 10.1007/s11125-020-09530-w (2021).

[101] E. Etkina, A. Van Heuvelen, D. T. Brookes, and D. Mills, Role of experiments in physics instruction-A process approach, Phys. Teach. 40, 351 (2002).

[102] T. Elmer, K. Mepham, and C. Stadtfeld, Students under lockdown: Comparisons of students' social networks and mental health before and during the COVID-19 crisis in Switzerland, PLoS One 15, e0236337 (2020).

[103] M. F. J. Fox, J. R. Hoehn, A. Werth, and H. J. Lewandowski, Lab instruction during the COVID-19 pandemic: Effects on student views about experimental physics in comparison with previous years, Phys. Rev. Phys. Educ. Res. 17, 010148 (2021).

[104] N. Hasan and Y. Bao, Impact of "e-learning crack-up" perception on psychological distress among college students during covid-19 pandemic: A mediating role of "fear of academic year loss", Children Youth Serv. Rev. 118, 105355 (2020).

[105] W. E. Copeland, E. McGinnis, Y. Bai, Z. Adams, H. Nardone, V. Devadanam, J. Rettew, and J. J. Hudziak, Impact of covid-19 pandemic on college student mental health and wellness, J. Am. Acad. Child Adolesc. Psych. 60, 134 (2021). 